\title{
Older Patient Satisfaction with Chronic Pain Management in the National Geriatric Hospital in Vietnam
}

This article was published in the following Dove Press journal: Patient Preference and Adherence

Huyen Thi Thanh Vu, (D) ${ }^{1,2}$ Hue Thi Mai, $\mathbb{D}^{3}$ Huong Thi Thu Nguyen, $\mathbb{D}^{1,2}$ Thu Thi Hoai Nguyen, (iD) 1,2 Thanh Xuan Nguyen, (1D) 1,2,4 Tam Ngoc Nguyen, (1D ${ }^{1,2}$ Thang Pham, ${ }^{1,2}$ Lan Thi Mai Nguyen,' Giang Thu Vu, Hai Quang Pham, ${ }^{6,7}$ Hai Thanh Phan, ${ }^{6,7}$ Bach Xuan Tran, ${ }^{3,8}$ Carl A Latkin, (1D ${ }^{8}$ Cyrus $\mathrm{SH} \mathrm{Ho}$, (iD) 9 Roger CM Ho, (D) ${ }^{6,10,11}$ Anh Trung Nguyen ${ }^{1,2}$

'Department of Geriatrics, Hanoi Medical University, Hanoi, Vietnam; ${ }^{2}$ Scientific Research Department, National Geriatric Hospital, Hanoi, Vietnam; ${ }^{3}$ Institute for Preventive Medicine and Public Health, Hanoi Medical University, Hanoi, Vietnam; ${ }^{4}$ Dinh Tien Hoang Institute of Medicine, Hanoi, Vietnam; ${ }^{5}$ Center of Excellence in Evidence-Based Medicine, Nguyen Tat Thanh University, Ho Chi Minh City, Vietnam; ${ }^{6}$ Institute for Global Health Innovations, Duy Tan University, Da Nang, Vietnam; ${ }^{7}$ Faculty of Medicine, Duy Tan University, Da Nang, Vietnam; ${ }^{8}$ Bloomberg School of Public Health, Johns Hopkins University, Baltimore, MD, USA;

${ }^{9}$ Department of Psychological Medicine, National University Hospital, Singapore, Singapore; ${ }^{10}$ Department of Psychological Medicine, Yong Loo Lin School of Medicine, National University of Singapore,

Singapore, Singapore; ' 'Institute for Health Innovation and Technology (iHealthtech),

National University of Singapore,

Singapore, Singapore

Correspondence: Huong Thi Thu Nguyen Scientific Research Department, National Geriatric Hospital, IA Phuong Mai - Dong

$\mathrm{Da}$, Hanoi 100000, Vietnam

Tel +84973056334

Email thuhuonglk@hmu.edu.vn
Purpose: The high prevalence of chronic pain and difficulties in pain management in older people are challenging for healthcare providers globally. Patient satisfaction regarding pain management is one of the measures to assess efficacy of pain control as well as healthcare services. Thus, our study aimed to evaluate the older patients' satisfaction with pain management and its associated factors in Vietnam.

Patients and Methods: A cross-sectional study was conducted at National Geriatric Hospital, Hanoi, Vietnam from May to October 2018. Face-to-face interviews were conducted on 495 older patients with chronic pain by using a structured questionnaire. The Pain Treatment Satisfaction Scale (PTSS) was used to assess the level of satisfaction with pain management. A Tobit regression model was used to estimate factors associated with satisfaction toward pain management.

Results: The mean total satisfaction score was $1.77(\mathrm{SD}=0.22)$. Older patients were most satisfied with the aspect of side effects of pain relief medication (mean $=0.66, \mathrm{SD}=0.56$ ). On the contrary, they were most dissatisfied with information provided about pain and its treatment and efficacy of pain relief medication. Outpatients were less satisfied with information provided, the impact of current medication and pain management in general compared to inpatients. The regression model showed that patients with severe pain tended to be more dissatisfied with pain management than those with no pain.

Conclusion: This study indicated that the general satisfaction with chronic pain management in older patients was quite good especially in the aspect of pain medication's side effects. However, dissatisfactory factors remained, including information provided about pain and efficacy of current pain medication. Intensive training regarding pain in geriatric care, health education communication for older people, and improved quality of medical services should be performed to ensure the quality of pain management, especially in the older population.

Keywords: chronic pain, elderly, pain management, satisfaction, Vietnam

\section{Introduction}

Chronic pain is one of the most common symptoms in older people that causes a significant burden on health care in both developed and developing countries. Chronic pain is defined as persistent or recurrent pain lasting longer than 3 months. ${ }^{1}$ In Asian countries, chronic pain in geriatric population was highly prevalent and ranged from $42 \%$ to $90.8 \%{ }^{2,3}$ Many studies mention chronic pain associated with advanced age because older people are more vulnerable to multiple chronic health conditions. $^{4-6}$ In Vietnam, a cross-sectional study indicated $62.43 \%$ had chronic 
pain, whereas the 60- over 90 years age group was more likely to suffer from chronic pain than others (accounting for $13.34 \%$ ). Also in this study, majority of the respondents reported that pain affected their daily lives. ${ }^{7}$

High prevalence and impact of chronic pain raises the urgent need for effective management for this group. So far, chronic pain management in older adults is one of the biggest challenges of geriatric medicine. Uncontrolled pain is associated with an increased risk of developing further complications, including not only physical dysfunctions but also mental states. ${ }^{8-12}$ Patients with chronic pain are often at risk for increasing rates of major depressive disorder. ${ }^{13}$ In addition, sleep disturbance is common in patients with chronic pain occurring in $50-89 \%$ of the chronic pain population, early treatment of chronic pain is important for minimizing sleep disturbance. ${ }^{8,9,14}$ The evidence has shown that patients adequately and timely treated with analgesics have a higher health-related quality of life in comparison with those with uncontrolled pain. ${ }^{12,15,16}$ Therefore, pain management should play a central role in healthcare delivery for older adults.

Along with population aging, older people are the major users of health care services and therefore patient satisfaction is a core aspect of health care quality and patient-centered care. ${ }^{17}$ Information on patient satisfaction with pain treatment is an important measure of treatment effectiveness, from which care planning and service quality improvement strategies are implemented. In addition, previous studies announced that patient satisfaction with their pain management has great effects on compliance and attachment to treatment plans. ${ }^{12,13,18,19}$ It is therefore necessary to assess patient satisfaction as well as its associated factors including patients' expectations, intensity of pain, level of pain relief and health-care professionals' attitude.

There have been many studies regarding the satisfaction of older people with pain management in the world. ${ }^{20-22}$ However, the level of satisfaction with chronic pain management varies by population. To our knowledge, there have been limited published studies that identify a comprehensive evaluation of several dimensions of chronic pain treatment satisfaction in Vietnam, especially in older population. Therefore, this study was conducted to measure the levels of patient satisfaction with pain management and determine its associated factors. We expected to accurately assess older patient satisfaction with pain management in the context of Vietnam, thereby informing evidence-based strategy to promote healthcare services in this group. This is also well-aligned with a project in health care for the elderly in the period of 2017-2025 under Decision No. 7618/QD-BYT in 2016, which emphasizes the role of improving health care services for the elderly in health facilities. $^{23}$

\section{Patients and Methods}

\section{Participants}

A cross-sectional study was conducted from May to October 2018 in National Geriatric Hospital, Hanoi, Vietnam. Patients were invited to participate in the study if they met the following criteria: 1) being 60 years old or above; 2) being hospitalized for at least 3 days at the time of the interview or being examined at outpatient department; 3) being diagnosed with chronic pain and being under treatment; 4) agreeing to enroll in the study. We excluded those with severe medical conditions (such as acute respiratory failure, acute stroke and acute renal failure), mental disorders or cognitive impairment. With the confidence level of 0.05 and the expected proportion of patients with chronic pain management among elderly patients of $47.1 \%$ (according to a previous study in Hong Kong ${ }^{24}$ ), we found the essential sample size to be 383 participants. To compensate for the patients who may not answer the questionnaire completely or may end up refusing to participate, an additional $10 \%$ was added to sample size. Eligible patients were recruited by convenience sampling until the final sample size of 421 was reached. However, after explaining the research, 25 of the selected patients decided not to enroll. All patients who did not complete the questionnaire were excluded from the final data. Data from a total of 495 patients completing the questionnaire were used for analysis.

\section{Data Collection}

Face-to-face interviews were performed in a private room to ensure a comfortable atmosphere and confidentiality. Data were collected by five well-trained nurses at the National Geriatric Hospital and advanced nursing students at Hanoi Medical University. They all had work and research experience in the field of geriatrics. Before conducting data collection, the study was throroughly explained to them (objectives, subjects, the questionnaire ...) and they were trained in interviewing the patients. A structured questionnaire was used to collect socio-demographic information (age, gender, health insurance, marital status, location, 
educational level, occupation, and average monthly income in Vietnam Dong), and clinical information (comorbidities: the presence of one or more additional conditions cooccurring with pain which were confirmed [diagnosed] by a medical doctor, current and history of smoking and frequency of drinking).

The Numeric Rating Scale (NRS) was employed to measure pain intensity at the time of the interview and average pain intensity during the previous week. Higher score indicated more severe pain and 0 indicated no pain. Pain intensity was categorized into four levels depending on the NRS score: no pain (0), mild pain (1-3), moderate pain (4-6) and severe pain (7-10). Besides, we asked the patients to report the locations of pain, number of "pain sites", medication administration routes, and the use of supplements for pain treatment purposes.

The Pain Treatment Satisfaction Scale (PTSS) was used to determine satisfaction toward chronic pain management. ${ }^{25}$ The initial questionnaire included 67 items divided into seven domains: general, information about pain and its treatment, medical care, current pain medication, routes of administration, satisfaction with pain management and care, and side effects. The psychometric properties of the scale were examined and the finalized questionnaire included 39 items which are grouped in five dimensions: information (5 items), medical care ( 8 items), the impact of current pain medication ( 8 items), satisfaction with pain medication (6 items), comprising of two subscales: medication characteristics (3 items) and efficacy ( 3 items), and side effects (12 items). The first four dimensions are rated on a five-point Likert scale $(1=$ strongly agree, $5=$ strongly disagree). Only side effects dimension is rated on a six-point Likert scale $(0=$ no experience, $5=$ extremely bothered).

We applied a standardized process for developing the Vietnamese version of the subset of PTSS to use in the study. This included the following steps: first we conducted a forward- backward translation from English into Vietnamese involving an English translator, geriatricians, palliative care doctors, and representative of the patients. Any discordance which emerged from the translation and review was discussed among the team and we had the translated version of the tool.

Secondly, we piloted this among a small sample of 20 patients. This pilot was to 1) assess the feasibility of using the translated tool among this patient group including: administered methods, time, flow, and 2) rapid assessment of patients' responses to understand any factors affecting validity of the measurement, for instance, floor and ceiling effects on measurement, understanding of the questions, ...

Finally, we conducted a post-pilot review among the research team to finalize the Vietnamese version of the questionnaire to be applied.

\section{Data Management and Analysis}

The database was managed by using REDCap (Research Electronic Data Capture) - a secure web-based software. Data were cleaned by an experienced researcher at National Geriatric Hospital. In order to ensure confidentiality, only approved members could access the database. STATA version 15 (Stata Corp. LP, College Station, USA) was used to analyze the data. Descriptive statistics were used to summarize socio-demographic and pain characteristics, comorbidities and medication use of participants. Mann Whitney test and Chi-squared test were used to examine the differences between the two groups (inpatient and outpatient groups). Statistical significance was considered when $\mathrm{p}<0.05$. A Tobit regression model was used to estimate factors associated with satisfaction toward pain management, censoring from 19 and 195 in the satisfaction score. A stepwise forward selection strategy with the threshold of $p<0.2$ was used to select potential variables for the regression model. We first enrolled the following variables in the stepwise model: age, gender, marital status, income, health insurance, location, education level, current smoking and history of smoking, co-morbidities, supplements, inpatient/outpatient, pain intensity at the time of the interview and the number of pain sites. With the threshold of 0.2 , nine potential predictors were chosen for further analysis.

\section{Results}

In a total of 495 patients, the mean age was $73.0(\mathrm{SD}=9.5)$ years old, the number of females in the inpatient group was significantly lower than those in the outpatient group $(\mathrm{p}<0.05)$. The majority of participants were retired $(84 \%)$, married (66\%), rural residents $(53.9 \%)$, and less than 80 years old $(72.7 \%)$. Proportion of co-morbidities in outpatients was higher than inpatients $(89.5 \%$ vs $96.6 \%$, respectively, $\mathrm{p}<0.01$ ), (Table 1 ).

Pain characteristics of participants were illustrated in Table 2, more than one third of the participants reported the sensation of pain in at least two locations (39.4\%). Regarding pain intensity at the time of the interview, moderate pain was observed in $50.7 \%$ of patients and 
Table I Socio-Demographic Characteristics of Participants

\begin{tabular}{|c|c|c|c|c|c|c|c|}
\hline \multirow{2}{*}{ Characteristics } & \multicolumn{2}{|c|}{ Inpatient } & \multicolumn{2}{|c|}{ Outpatient } & \multicolumn{2}{|l|}{ Total } & \multirow[t]{2}{*}{ p-value } \\
\hline & $\mathbf{n}$ & $\%$ & $\mathbf{n}$ & $\%$ & $\mathbf{n}$ & $\%$ & \\
\hline \multicolumn{8}{|l|}{ Age (years) } \\
\hline$<80$ & 166 & 83.0 & 194 & 65.8 & 360 & 72.7 & $<0.01$ \\
\hline$\geq 80$ & 34 & 17.0 & 101 & 34.2 & 135 & 27.3 & \\
\hline \multicolumn{8}{|l|}{ Gender } \\
\hline Male & 55 & 27.5 & 119 & 40.3 & 174 & 35.2 & $<0.05$ \\
\hline Female & 145 & 72.5 & 176 & 59.7 & 321 & 64.8 & \\
\hline \multicolumn{8}{|l|}{ Occupation } \\
\hline Retired & 163 & 81.5 & 253 & 85.8 & 416 & 84.0 & 0.20 \\
\hline Employed & 37 & 18.5 & 42 & 14.2 & 79 & 16.0 & \\
\hline \multicolumn{8}{|l|}{ Marital status } \\
\hline Married & 147 & 73.9 & 177 & 60.6 & 324 & 66.0 & $<0.05$ \\
\hline Single & 2 & 1.0 & 0 & 0.0 & 2 & 0.4 & \\
\hline Divorced/separated & I & 0.5 & 0 & 0.0 & I & 0.2 & \\
\hline Widowed & 49 & 24.6 & 115 & 39.4 & 164 & 33.4 & \\
\hline \multicolumn{8}{|l|}{ Monthly income } \\
\hline No income & 49 & 24.6 & 96 & 32.5 & 145 & 29.4 & $<0.01$ \\
\hline$<3.000 .000$ VND & 49 & 24.6 & 122 & $4 I .4$ & 171 & 34.6 & \\
\hline $3.000 .000-5.000 .000$ VND & 81 & 40.7 & 58 & 19.7 & 139 & 28.1 & \\
\hline 5.000.000-7.000.000 VND & 15 & 7.5 & 15 & 5.1 & 30 & 6.1 & \\
\hline$>7.000 .000 \mathrm{VND}$ & 5 & 2.5 & 4 & 1.4 & 9 & 1.8 & \\
\hline Had health insurance (Yes) & 190 & 95.0 & 278 & 94.2 & 468 & 94.6 & 0.71 \\
\hline \multicolumn{8}{|l|}{ Location } \\
\hline Rural & 116 & 58.0 & 151 & 51.2 & 267 & 53.9 & 0.14 \\
\hline Urban & 84 & 42.0 & 144 & 48.8 & 228 & 46.1 & \\
\hline \multicolumn{8}{|l|}{ Educational levels } \\
\hline Primary school & 39 & 19.5 & 65 & 22.0 & 104 & 21.0 & 0.13 \\
\hline Secondary school & 54 & 27.0 & 89 & 30.2 & 143 & 28.9 & \\
\hline High school & 70 & 35.0 & 75 & 25.4 & 145 & 29.3 & \\
\hline University & 15 & 7.5 & 16 & 5.4 & 31 & 6.3 & \\
\hline Post-graduation & 2 & 1.0 & 3 & 1.0 & 5 & 1.0 & \\
\hline Others & 20 & 10.0 & 47 & 15.9 & 67 & 13.5 & \\
\hline Current smoking (Yes) & 7 & 4.1 & 17 & 8.0 & 24 & 6.2 & 0.12 \\
\hline History of smoking (Yes) & 33 & 19.6 & 60 & 29.4 & 93 & 25.0 & $<0.05$ \\
\hline \multicolumn{8}{|l|}{ Frequency of smoking } \\
\hline Once in several month & 10 & 45.5 & 16 & 30.2 & 26 & 34.7 & 0.18 \\
\hline Once a month & 0 & 0.0 & 7 & 13.2 & 7 & 9.3 & \\
\hline Once a week & 3 & 13.6 & 7 & 13.2 & 10 & 13.3 & \\
\hline 2-5 times/week & 2 & 9.1 & 12 & 22.6 & 14 & 18.7 & \\
\hline Everyday & 7 & 31.8 & 11 & 20.8 & 18 & 24.0 & \\
\hline \multirow[t]{2}{*}{ Comorbidities (Yes) } & 178 & 89.5 & 285 & 96.6 & 463 & 93.7 & $<0.01$ \\
\hline & Mean & SD & Mean & SD & Mean & SD & \\
\hline Age (years) & 70.4 & 8.7 & 74.6 & 9.7 & 73.0 & 9.5 & $<0.01$ \\
\hline
\end{tabular}


Table 2 Pain Characteristics of Participants

\begin{tabular}{|c|c|c|c|c|c|c|c|}
\hline \multirow[t]{2}{*}{ Characteristics } & \multicolumn{2}{|c|}{ Inpatient } & \multicolumn{2}{|c|}{ Outpatient } & \multicolumn{2}{|l|}{ Total } & \multirow[t]{2}{*}{ p-value } \\
\hline & $\mathbf{n}$ & $\%$ & $\mathbf{n}$ & $\%$ & $\mathbf{n}$ & $\%$ & \\
\hline \multicolumn{8}{|l|}{ Number of pain sites } \\
\hline 1 & 118 & 59.0 & 182 & 61.7 & 300 & 60.6 & 0.55 \\
\hline$\geq 2$ & 82 & 41.0 & 113 & 38.3 & 195 & 39.4 & \\
\hline \multicolumn{8}{|l|}{ Pain intensity (at the time of the interview) } \\
\hline No pain & 25 & 12.5 & 9 & 3.1 & 34 & 6.9 & $<0.01$ \\
\hline Mild & 58 & 29.0 & 34 & 11.5 & 92 & 18.6 & \\
\hline Moderate & 86 & 43.0 & 165 & 55.9 & 251 & 50.7 & \\
\hline Severe & 31 & 15.5 & 87 & 29.5 & 118 & 23.8 & \\
\hline \multicolumn{8}{|l|}{ Pain location } \\
\hline Head-Face-Neck & 71 & 35.5 & 119 & 40.3 & 190 & 38.4 & 0.28 \\
\hline Shoulder-Arm-Elbow-Hand & 42 & 21.0 & 54 & 18.3 & 96 & 19.4 & 0.46 \\
\hline Stomach-Abdomen & 22 & 11.0 & 38 & 12.9 & 60 & 12.1 & 0.53 \\
\hline Back-Hip & 48 & 24.0 & 50 & 17.0 & 98 & 19.8 & 0.05 \\
\hline Knee-Foot-Leg & 81 & 40.5 & 95 & 32.2 & 176 & 35.6 & 0.06 \\
\hline Others & 45 & 22.5 & 81 & 27.5 & 126 & 25.5 & 0.21 \\
\hline \multicolumn{8}{|l|}{ Route of administration - Oral } \\
\hline Yes & 138 & 69.0 & 240 & 81.4 & 378 & 76.4 & $<0.01$ \\
\hline No & 62 & 31.0 & 55 & 18.6 & 117 & 23.6 & \\
\hline \multicolumn{8}{|l|}{ Route of administration - Intravenous } \\
\hline Yes & 7 & 3.5 & 70 & 23.7 & 77 & 15.6 & $<0.01$ \\
\hline No & 193 & 96.5 & 225 & 76.3 & 418 & 84.4 & \\
\hline \multicolumn{8}{|l|}{ Route of administration - Patches } \\
\hline Yes & 5 & 2.5 & I & 0.3 & 6 & 1.2 & $<0.05$ \\
\hline No & 195 & 97.5 & 294 & 99.7 & 489 & 98.8 & \\
\hline \multirow{2}{*}{$\begin{array}{l}\text { Supplements } \\
\text { (herbal/functional foods)(Yes) }\end{array}$} & 43 & 21.9 & 20 & 6.9 & 63 & 12.9 & $<0.01$ \\
\hline & Mean & SD & Mean & SD & Mean & SD & \\
\hline Pain intensity at the time of the interview & 4 & 2.3 & 5 & 1.8 & 5 & 2.1 & $<0.01$ \\
\hline Pain intensity during the previous week & 6 & 1.6 & 7 & 1.2 & 6 & $\mathrm{I} .4$ & $<0.01$ \\
\hline
\end{tabular}

only $6.9 \%$ did not have pain. The mean pain intensity score during the previous week and at the time of the interview was significantly higher in the outpatient group in comparison with the inpatient one $(p<0.01)$. Most participants commonly reported pain at head-face-neck $(38.4 \%)$, the least reported location was stomachabdomen (12.1\%). Among three routes of pain medication administration, the majority was oral route $(76.4 \%)$, followed by intravenous route $(15.6 \%)$, and patches $(1.2 \%)$. When asked about the use of supplements (herbal/functional foods) for pain treatment purposes, nearly 13.0\% answered "Yes".

The level of patient satisfaction toward pain management is shown in Table 3. While patients were most satisfied with pain treatment having little side effects (mean $=0.66, \mathrm{SD}=$ 0.56 ), they were most dissatisfied with information provided (mean=2.67, $\mathrm{SD}=0.82$ ), pain medication (mean=2.29, $\mathrm{SD}=0.56$ ) especially in efficacy subscale (mean $=2.42$, $\mathrm{SD}=0.67$ ), and impact of current medication ( mean $=2.28$, $\mathrm{SD}=0.43$ ). Of note, outpatients were less satisfied with information provided $(\mathrm{p}=0.01)$, the impact of current medication $(p<0.01)$, and pain management in general compared to inpatients $(p<0.05)$.

Table 4 summarizes the Tobit regression results exploring factors associated with the total satisfaction score. The results show that the number of pain locations, pain intensity, current smoking and having health insurance were significantly associated with the total satisfaction score. 
Table 3 Patient Satisfaction Toward Pain Management

\begin{tabular}{|c|c|c|c|c|c|c|c|c|}
\hline \multirow[t]{2}{*}{ Characteristics } & \multirow[t]{2}{*}{ Score Range } & \multicolumn{2}{|c|}{ Inpatient } & \multicolumn{2}{|c|}{ Outpatient } & \multicolumn{2}{|l|}{ Total } & \multirow[t]{2}{*}{ p-value } \\
\hline & & Mean & SD & Mean & SD & Mean & SD & \\
\hline Information (5 items) & $5-25$ & 2.55 & 0.99 & 2.75 & 0.70 & 2.67 & 0.82 & 0.01 \\
\hline Medical care (8 items) & $8-40$ & 2.03 & 0.24 & 1.99 & 0.20 & 1.99 & 0.21 & 0.46 \\
\hline Impact of current medication (8 items) & $8-40$ & 2.18 & 0.39 & 2.34 & 0.46 & 2.28 & 0.43 & $<0.01$ \\
\hline Satisfaction with pain medication (6 items) & $6-30$ & 2.35 & 0.61 & 2.26 & 0.52 & 2.29 & 0.56 & 0.74 \\
\hline Medication characteristics subscale ( 3 items) & $3-15$ & 2.19 & 0.46 & 2.17 & 0.45 & 2.18 & 0.45 & 0.74 \\
\hline Efficacy subscale s(3 items) & $3-15$ & 2.51 & 0.77 & 2.35 & 0.60 & 2.41 & 0.67 & 0.10 \\
\hline Side effects ( 12 items) & $0-60$ & 0.66 & 0.62 & 0.65 & 0.52 & 0.66 & 0.56 & 0.53 \\
\hline Total satisfaction score ( 39 items) & $27-195$ & 1.75 & 0.22 & 1.79 & 0.22 & 1.77 & 0.22 & $<0.05$ \\
\hline
\end{tabular}

Table 4 Factors Associated with Patient Satisfaction Toward Pain Management

\begin{tabular}{|c|c|c|}
\hline \multirow[t]{2}{*}{ Characteristics } & \multicolumn{2}{|c|}{ Total Satisfaction Score } \\
\hline & Coef & $95 \% \mathrm{Cl}$ \\
\hline Outpatient (Ref: inpatient) & 0.12 & $(-1.89-2.12)$ \\
\hline Age & 0.06 & $(-0.04-0.16)$ \\
\hline \multicolumn{3}{|c|}{ Number of pain locations (Ref: $\leq 1$ location) } \\
\hline > I location & $-2.37 * *$ & $(-4.29--0.45)$ \\
\hline \multicolumn{3}{|l|}{ Levels of pain (Ref: No pain) } \\
\hline Moderate & $1.91 *$ & $(-0.28-4.10)$ \\
\hline Severe & $4.04 * * *$ & $(1.20-6.89)$ \\
\hline \multicolumn{3}{|l|}{ Had health insurance (Ref: Yes) } \\
\hline No & $6.07 * *$ & $(0.90-11.24)$ \\
\hline Current smoking (Ref: No) & $-4.01 * *$ & $(-7.80--0.23)$ \\
\hline \multicolumn{3}{|l|}{ Education (Ref: Primary school) } \\
\hline High school & 2.92 & $(-0.92-6.76)$ \\
\hline \multicolumn{3}{|c|}{ Monthly income (Ref: No income) } \\
\hline$<3.000 .000$ VND & -1.42 & $(-3.43-0.60)$ \\
\hline$>7.000 .000$ VND & $-6.52^{*}$ & $(-14.07-1.04)$ \\
\hline Using supplements (Ref: No) & -1.93 & $(-4.7 I-0.85)$ \\
\hline Constant & $70.78 * * *$ & $(67.16-74.41)$ \\
\hline
\end{tabular}

Note: $* * * p<0.01, * * p<0.05, * p<0.1$.

In more detail, those who perceived severe pain tended to be less satisfied with the pain management than those without it (Coef: 4.04, 95\% CI: 1.20-6.89). In contrast, patients who reported pain in at least two locations were more likely to be satisfied with the pain management than their counterparts (Coef: $-2.37,95 \% \mathrm{CI}$ : $-4.29--0.45$ ). Of note, current smokers were more satisfied with pain management compared to their counterparts (Coef: -4.01 , 95\% CI: $-7.80--0.23$ ).

\section{Discussion}

The purpose of this study was to assess the level of patient satisfaction toward treatment of chronic pain and to explore the relationship between satisfaction and some factors. To the best of our knowledge, this is the first descriptive study performed in older patients which also evaluated patient satisfaction in many aspects in the context of Vietnam. Thus, the results of this present study render empirical findings which are the premise for further studies.

Our study showed that the level of satisfaction with pain management in general was quite good which was consistent with previous studies, McCracken et al reported that $60 \%$ of patients were satisfied with treatment. ${ }^{18,26}$ Similarly, Tawil et el provided optimistic data that $84.7 \%$ of the patients were either satisfied or strongly satisfied. ${ }^{27}$ This finding was also in line with recently published research on pain in Vietnam, which indicated that $58.97 \%$ of respondents were either satisfied or extremely satisfied with their pain control. ${ }^{7}$ However, the previous study did not provide specific aspects of patient satisfaction with pain management and did not focus on the older age population. In particular, our study indicated that side effects of current pain relievers was the most satisfactory aspect of pain treatment. Most patients responded that they did not experience any side effects of pain medication or if they did, these effects did not bother them at all (mean score of side effect dimension $=0.66, \mathrm{SD}=0.56$ ). Rating of satisfaction with medical care was also high in this study. The finding was in congruence with previous literature on patient engagement and satisfaction with care. ${ }^{18,28-30}$

Meanwhile, out of the seven dimensions of PTSS scale, information about pain and its treatment obtained the highest mean score, suggesting that it was the most dissatisfactory aspect of pain treatment in this population. This result 
might vary in different populations. According to results from Wong et al, the least satisfactory aspect in pain treatment was impact of the current pain medication. ${ }^{28}$ That might be due to the lack of pain specialists to treat patients with pain and the fact that medical staff working with patients with pain had not been trained in pain management in universities. Moreover, to date, there has not been an official guideline for pain treatment in Vietnam, especially in geriatric care. Furthermore, in developing countries, overcrowding of patients in major hospitals and comorbidities in older patients lead to limited time for examination and to give information on pain management to each patient. The results of these analyses provide additional evidence that satisfaction is not achieved by only maintaining low level of pain and/or providing pain relief, but also by being concerned about care service issues and informing patients.

In our results, current pain medication, especially in efficacy subscale was also a dissatisfactory aspect of pain treatment. Patients responded that they were not satisfied with the time it takes for the pain relievers to work, the level and duration of pain relief. As it has been discussed in the existing literature, the satisfaction with efficacy of pain medication may be directly affected by patients' needs and expectations. ${ }^{31-34}$ If these are unmet, it may lead to dissatisfaction with services. Thus, it would be more prudent for healthcare providers to assess individual needs and expectations for pain relief by discussing those with older patients. In this respect, nurses can play a key role as they are "closest" to them.

Of note, outpatients were less satisfied with information provided, the impact of current medication, and the pain management in general compared to inpatients. We hypothesize that outpatients tend to self-treat at home after receiving a prescription from a physician, so they might not receive the necessary information on a regular, timely basis like inpatients. Pain treatment might be more effective for inpatients due to the aggressive interventions of healthcare workers. Unmet needs in the impact of current medication explained the fact that older patients tend to take supplements (herbal/functional foods) to relieve pain. The finding showed that $12.9 \%$ of participants used supplements for pain relief purposes and $21.9 \%$ of inpatients used them before admission. For these patients, providing sufficient information and treatment information is essential. The regression model showed that patients who perceived severe pain tended to be less satisfied with the pain management than those with no pain. The relationship between the pain intensity and satisfaction in our study is consistent with numerous other studies. ${ }^{25,28,35}$ Patients with severe pain will experience a decline in mental and physical health. A combination of inadequate treatment, high pain intensity, and unmet needs in pain relief and limitation of healthcare system may lead to dissatisfaction with services.

This study suggests several implications. First, a training program should be designed and provided to geriatric health professionals as well as physicians and nurses to improve the effectiveness of pain treatment in older patients. Second, comprehensive assessment of pain characteristics as well as satisfaction with pain treatment should be evaluated regularly in clinical practice. Feedback from patients may be used to alter and improve the quality of health care delivery. Third, hospitals and healthcare professionals should create conditions for older patients to be provided with complete information about pain and pain treatment. A study which assesses knowledge and attitude of health care providers regarding pain management in older people should be conducted in the future.

Our study is subject to several limitations. First, this project was conducted in a geriatric hospital which reduced our ability to find out the factors associated with satisfaction regarding pain management for older people. Little information about the origins of pain was also a limitation of the research. Additionally, this limitation decreases our generalizability, implying that we should be cautious when applying our findings to other settings. Besides, the nature of a cross-sectional design does not allow to draw causal relationships between variables and the outcome of interests. Future studies employing a longitudinal design could help address these limitations. Also, since the patients were allowed to refuse to answer any questions during the interview, data may be missing, thus, it might affect the generalizability of the findings.

\section{Conclusion}

This study indicated that the general satisfaction with chronic pain management in older patients was quite good especially in the aspect of pain relievers' side effects. However, dissatisfactory dimensions remained, including pain information provided and efficacy of current pain medication. Intensive training regarding pain in geriatric care, health education communication for older people and improved quality of medical 
services should be performed to ensure the quality of pain management, especially in older populations.

\section{Abbreviations}

PTSS, Pain Treatment Satisfaction Scale (PTSS); REDCap, Research Electronic Data Capture.

\section{Data Sharing Statement}

The datasets of this study are available from the corresponding author on reasonable request.

\section{Ethics Approval and Informed Consent}

The study was approved by the Ethics Committee of the National Geriatric Hospital Review Board, (Reference Number: 635/IRB-NGH). Written informed consent was obtained from all participants. This study complied with the Declaration of Helsinki.

\section{Acknowledgment}

We would like to express our deepest gratitude for the great support of Ms Anh Lan Nguyen, National Geriatric Hospital, Hanoi, Vietnam during research implem entation.

\section{Author Contributions}

All authors made substantial contributions to conception and design, acquisition of data, or analysis and interpretation of data; took part in drafting the article or revising it critically for important intellectual content; agreed to submit to the current journal; gave final approval of the version to be published; and agree to be accountable for all aspects of the work.

\section{Funding}

There was no funding for this analysis.

\section{Disclosure}

The author reports no potential conflicts of interest in this work.

\section{References}

1. Treede RD, Rief W, Barke A, et al. A classification of chronic pain for ICD-11. Pain. 2015;156(6):1003-1007.

2. Mohamed ZLR, Hairi NN. A systematic review of the prevalence and measurement of chronic pain in asian adults. Pain Manag Nurs. 2015;16(3):440-452. doi:10.1016/j.pmn.2014.08.012
3. Ng KF, Tsui SL, Chan WS. Prevalence of common chronic pain in Hong Kong adults. Clin J Pain. 2002;18(5):275-281. doi:10.1097/ 00002508-200209000-00001

4. Blyth FM, March LM, Brnabic AJ, Jorm LR, Williamson M, Cousins MJ. Chronic pain in Australia: a prevalence study. Pain. 2001;89(2-3):127-134. doi:10.1016/s0304-3959(00)00355-9

5. Rapo-Pylkkö SHM, Liira H. Chronic pain among communitydwelling elderly: a population-based clinical study. Scand J Prim Health Care. 2016;34(2):159-164. doi:10.3109/02813432.2016.1160628

6. Stompór M, Grodzicki T, Stompór T, Wordliczek J, Dubiel M, Kurowska I. Prevalence of chronic pain, particularly with neuropathic component, and its effect on overall functioning of elderly patients. Med Sci Monit. 2019;25:2695. doi:10.12659/MSM.911260

7. Chuong NV, Pho DC, Thuy NTT, et al. Pain incidence, assessment, and management in Vietnam: a cross-sectional study of 12,136 respondents. J Pain Res. 2019;12:769-777. doi:10.2147/JPR.S184713

8. Fine PG. Long-term consequences of chronic pain: mounting evidence for pain as a neurological disease and parallels with other chronic disease states. Pain Med. 2011;12(7):996-1004. doi:10.1111/j.1526-4637.2011.01187.x

9. Morin CM, Gibson D, Wade J. Self-reported sleep and mood disturbance in chronic pain patients. Clin J Pain. 1998;14(4):311-314. doi:10.1097/00002508-199812000-00007

10. Smith BH, Elliott AM, Chambers WA, et al. The impact of chronic pain in the community. Fam Pract. 2001;18(3):292-299. doi:10.1093/fampra/18.3.292

11. Von Korff M, Crane P, Lane M, et al. Chronic spinal pain and physical-mental comorbidity in the United States: results from the national comorbidity survey replication. Pain. 2005;113(3):331-339. doi:10.1016/j.pain.2004.11.010

12. McCarberg BH, Todd NB, Palmer T, Penles L. The impact of pain on quality of life and the unmet needs of pain management: results from pain sufferers and physicians participating in an internet survey. $\mathrm{Am}$ $J$ Ther. 2008;15(4):312-320. doi:10.1097/MJT.0b013e31818164f2

13. Ohayon MM, Schatzberg AF. Using chronic pain to predict depressive morbidity in the general population. Arch Gen Psychiatry. 2003;60(1):39-47. doi:10.1001/archpsyc.60.1.39

14. Marty M, Rozenberg S, Duplan B, et al. Quality of sleep in patients with chronic low back pain: a casecontrol study. Eur Spine J. 2008;17 (6):839-844. doi:10.1007/s00586-008-0660-7

15. Katz N. The impact of pain management on quality of life. $J$ Pain Symptom Manage. 2002;24(1 Suppl):S38-47. doi:10.1016/s08853924(02)00411-6

16. Dueñas M, Ojeda B, Salazar A, et al. A review of chronic pain impact on patients, their social environment and the health care system. J Pain Res. 2016;9:457-467. doi:10.2147/JPR.S105892

17. Baker TA, Krok-Schoen JL, O'Connor ML, Brooks AK. The influence of pain severity and interference on satisfaction with pain management among middle-aged and older adults. Pain Res Manag. 2016;2016:9561024. doi:10.1155/2016/9561024

18. Hirsh AT, Atchison JW, Berger JJ, et al. Patient satisfaction with treatment for chronic pain: predictors and relationship to compliance. Clin J Pain. 2005;21(4):302-310. doi:10.1097/01.ajp.0000113057.92184.90

19. Baker TA, O'Connor ML, Roker R, Krok JL. Satisfaction with pain treatment in older cancer patients: identifying variants of discrimination, trust, communication, and self-efficacy. $J$ Hosp Palliat Nurs. 2013;15(8):10.1097/NJH.0b013e3182a12c24. doi:10.1097/NJH.0b0 $13 \mathrm{e} 3182 \mathrm{a} 12 \mathrm{c} 24$

20. Innis J, Bikaunieks N, Petryshen P, Zellermeyer V, Ciccarelli L. Patient satisfaction and pain management: an educational approach. J Nurs Care Qual. 2004;19(4):322-327. doi:10.1097/00001786200410000-00006

21. Simmons SF, Schnelle JF, Saraf AA, et al. Pain and satisfaction with pain management among older patients during the transition from acute to skilled nursing care. Gerontologist. 2016;56(6):1138-1145. doi:10.1093/geront/gnv058 
22. Farooq F, Khan R, Ahmed A. Assessment of patient satisfaction with acute pain management service: monitoring quality of care in clinical setting. Indian J Anaesth. 2016;60(4):248-252. doi:10.4103/00195049.179450

23. The Ministry of Health. The Decision on the Approval of the Healthcare Project for the Ederly in the Period of 2017-2025. 2016.

24. Tse M, Wan VTC, Wong AMH. Pain and pain-related situations surrounding community-dwelling older persons. $J$ Clin Nurs. 2013;22(13-14):1870-1879. doi:10.1111/jocn.12238

25. Evans CJ, Trudeau E, Mertzanis P, et al. Development and validation of the pain treatment satisfaction scale (PTSS): a patient satisfaction questionnaire for use in patients with chronic or acute pain. Pain 2004;112(3):254-266. doi:10.1016/j.pain.2004.09.005

26. McCracken LM, Klock PA, Mingay DJ, Asbury JK, Sinclair DM. Assessment of satisfaction with treatment for chronic pain. J Pain Symptom Manage. 1997;14(5):292-299. doi:10.1016/s0885-3924(97) 00225-x

27. Tawil S, Iskandar K, Salameh P. Pain management in hospitals: patients' satisfaction and related barriers. Pharm Pract (Granada). 2018;16(3):1268. doi:10.18549/PharmPract.2018.03.1268

28. Wing S, Wong P, Phoon P, Chow F, Wong S, Fielding R. The reliability and validity of the cantonese version of the pain treatment satisfaction scale (ChPTSS) in a sample of chinese patients with chronic pain. Pain Med. 2015;16(12):2316-2323. doi:10.1111/ pme. 12790
29. Koyama T, McHaffie JG, Laurienti PG, Coghill RC. The subjective experience of pain: where expectations become reality. Proc Natl Acad Sci U S A. 2005;102(36):12950-12955. doi:10.1073/pnas.04 08576102

30. Egan M, Cornally N. Identifying barriers to pain management in long-term care. Nurs Older People. 2013;25(7):25-31. doi:10.7748/ nop2013.09.25.7.25.e455

31. Wen KY, Gustafson DH. Needs assessment for cancer patients and their families. Health Qual Life Outcomes. 2004;2(1):11. doi:10.11 86/1477-7525-2-11

32. Noble PC, Conditt MA, Cook KF, Mathis KB. The John insall award: patient expectations affect satisfaction with total knee arthroplasty. Clin Orthop Relat Res. 2006;452:35-43. doi:10.1097/01.blo.0000 238825.63648.1e

33. Geurts JW, Willems PC, Lockwood C, van Kleef M, Kleijnen J, Dirksen C. Patient expectations for management of chronic non-cancer pain: a systematic review. Health Expect. 2017;20 (6):1201-1217. doi:10.1111/hex.12527

34. Fielding R, Hedley AJ, Cheang J. Patients' satisfaction is based firmly on their expectations. Br Med J. 1997;314:227.

35. Carlson J, Youngblood R, Dalton JA, Blau W, Lindley C. Is patient satisfaction a legitimate outcome of pain management? J Pain Symptom Manage. 2003;25(3):264-275. doi:10.1016/s0885-3924(02) 00677-2
Patient Preference and Adherence

\section{Publish your work in this journal}

Patient Preference and Adherence is an international, peer-reviewed, open access journal that focusing on the growing importance of patient preference and adherence throughout the therapeutic continuum. Patient satisfaction, acceptability, quality of life, compliance, persistence and their role in developing new therapeutic modalities and compounds to optimize clinical outcomes for existing disease

\section{Dovepress}

states are major areas of interest for the journal. This journal has been accepted for indexing on PubMed Central. The manuscript management system is completely online and includes a very quick and fair peer-review system, which is all easy to use. Visit http:// www.dovepress.com/testimonials.php to read real quotes from published authors. 